\title{
Ophthalmological Manifestations in Chronic Hemodialyzed Patients: A 132 Cases Study in Abidjan
}

\author{
François Xavier Kouassi ${ }^{*}$, Chiatse Ellalie Koman', Massesse Soumahoro', \\ Alla N'goran Simeon Kra ${ }^{1}$, Liliane Fortunette Angelus Ouonnebo ${ }^{2}$, \\ Ange-Aristide Konan Kouakou ${ }^{1}$, Cophican Arthur Ulrich Dibi ${ }^{1}$ \\ ${ }^{1}$ Ophthalmology Department, Cocody University Hospital, Abidjan, Côte d'Ivoire \\ ${ }^{2}$ Ophthalmology Department, Yopougon University Hospital, Abidjan, Côte d'Ivoire \\ Email: *xavkouassi@yahoo.fr
}

How to cite this paper: Kouassi, F.X., Koman, C.E., Soumahoro, M., Kra, A.N.S., Ouonnebo, L.F.A., Kouakou, A.-A.K. and Dibi, C.A.U. (2019) Ophthalmological Manifestations in Chronic Hemodialyzed Patients: A 132 Cases Study in Abidjan. Open Journal of Ophthalmology, 9, 9-17. https://doi.org/10.4236/ojoph.2019.91002

Received: October 22, 2018

Accepted: December 23, 2018

Published: December 26, 2018

Copyright $\odot 2019$ by authors and Scientific Research Publishing Inc. This work is licensed under the Creative Commons Attribution International License (CC BY 4.0).

http://creativecommons.org/licenses/by/4.0/

cc) (7) Open Access

\begin{abstract}
Purpose: The aim of this study was to describe the eye signs seen in patients on chronic hemodialysis at Cocody University Hospital and the factors influencing their occurrence. Material and Methods: We carried out in the Ophthalmology Department of Cocody University Hospital a cross-sectional study over 15 months. It focused on 132 patients on chronic hemodialysis followed in the hemodialysis department of Cocody University Hospital. Results: Hypertensive nephropathy was the leading cause of chronic renal failure (58\%). The most common ocular functional sign was loss of visual acuity (LVA) (38\%), followed by ocular pruritus (22\%). Twenty-one percent $(21 \%)$ of our patients were visually impaired (MAVLC $<3 / 10$ ). The adnexal lesions were polymorphic. The most commonly encountered were dry eye (14\%) and eyelid edema ( $8 \%)$. The anterior segment involvement was dominated by cataract (28\%). Hypertensive retinopathy was noted in $42 \%$ of patients. The frequency of ophthalmological manifestations decreased as the duration of dialysis increased. Discussion: Eye manifestations in people with chronic renal failure and on hemodialysis are variable. Several factors are involved, mainly hypertension; first and foremost is hypertension. Correction of these factors is necessary to prevent blindness.
\end{abstract}

\section{Keywords}

Renal Failure, Chronic Hemodialysis, Eye Signs

\section{Introduction}

Chronic renal failure (CRF) is the progressive and irreversible decrease in glo- 
merular filtration and endocrine function of the kidney, related to the destruction of nephrons. It leads to an accumulation of nitrogenous waste marked by an increase in plasma creatinine and urea that spontaneously develops to the terminal stage where dialysis is then essential for the survival of the patient [1].

However, chronic dialysis is a source of multiple complications including eye manifestations. Several studies in Africa have focused on the description of these eye manifestations, namely those of Ndiaye [2] in Senegal and Bourquia in Morocco [3].

On the other hand, in Côte d'Ivoire, we did not find any data available on this subject, which justifies the present study, whose aim was to clarify these eye manifestations in order to treat them and contribute to the improvement of the quality of life of patients on chronic hemodialysis in our context. The aim of this study was to describe the eye manifestations encountered in chronic renal failure patients on dialysis.

\section{Material and Methods}

Material: Our study was prospective and was carried out in the Ophthalmology Department of Cocody University Hospital. It focused on chronic hemodialysis patients followed in the hemodialysis center. All patients in the end-stage of CRF, who had been on hemodialysis for more than 6 months and who had undergone a complete ophthalmological examination, were included. Chronic hemodialysis patients with a medical record of nephrology that could not be used or who could not move for an ophthalmological examination because of their poor general condition or who refused to participate in the study were not included.

Our sample was 132 patients with respect to the above selection criteria.

Methods: The study was carried out from May 2016 to July 2017. It was a cross-sectional and descriptive study. The data were collected using a survey form.

In the ophthalmology department, data collection was done from the interview and the clinical examination. In the hemodialysis department, the collection has been possible thanks to the files of patients. The survey sheet was filled in by a team trained for this purpose. For each patient, the studied parameters concerned: age, gender, occupation-medical histories (hypertension, diabetes, HIV and others), clinical and paraclinical data on the CRF. These included the presumed etiology of CRF, systolic-diastolic blood pressure taken before dialysis, the presence or absence of general complications (cardiac, infectious, digestive, neurological and endocrine), hemoglobin $(\mathrm{g} / \mathrm{dl})$ and associated medical treatment. Anyone whose hemoglobin level was below $12 \mathrm{~g} / \mathrm{dl}$ was considered anemic. Retinophotography, retinal angiography and automatic visual field were performed. Ophthalmological examination was bilateral and comparative. It consisted first of all in measuring the best corrected visual acuity. With the slit lamp, the appendages and the anterior segment were examined. The intra ocular pres- 
sure was measured with a Goldmann applanation tonometer. Examination of the fundus, after maximal pupillary dilatation, with Goldmann's 3-mirror glass or with Volk's lens, allowed retinal and vitreous analysis. Ocular motility was appreciated in the different positions of the gaze.

The data collected were processed using the Stata software. Chi-2 tests were used to compare qualitative variables. The threshold of significance is $5 \%$.

As to the limitations of the study, not all patients in the nephrology department could be examined. This was due on the one hand to their general condition which did not allow the complete ophthalmological examination and on the other hand to the refusal to participate in the study.

\section{Results}

\subsection{Socio-Demographic Aspects (Table 1)}

- The average age of patients was 45.18 +/- (standard deviation) years with extremes between 13 and 74 years.

- The male gender was predominant in $59.84 \%$ of cases that is a sex ratio of 1.49 .

- Informal sector workers were the most numerous (53.78\%).

\subsection{Clinical Features}

- General medical histories were dominated by hypertension (61.53\%). Ophthalmological histories were represented by ametropia (78.12\%). Other general histories were Acquired Immunodeficiency Syndrome (AIDS) (12.17\%); chronic Glomerulonephritis (7.05\%) and diabetes (6.41\%).

- Hypertensive nephropathy was the presumed main cause of CRF (58.33\%). Nephropathies related to HIV/AIDS and diabetes accounted for $10.60 \%$ and $8.33 \%$, respectively.

- The most common functional sign was loss of visual acuity (LVA) (37.12\%), followed by eye pruritus $(22.72 \%)$. Eyes with visual impairment $(\mathrm{AVL}<3 / 10)$ were observed in $20.83 \%$ of cases.

- Lesions in the appendages were polymorphous, but the most commonly encountered were dry eye (13.51\%) revealed by the Break-up time (13.5\%) and eyelid edema (08.10\%). Conjunctival hyperemia and Conjunctival calcifications accounted for $7 \%$ and $5 \%$, respectively.

- Anterior segment involvement was dominated by cataract and superficial punctate keratitis (SPK) observed in $28.03 \%$ and $17.42 \%$ of cases, respectively (Table 2).

- The majority of patients had normal intraocular pressure (90.15\%). Only $7.96 \%$ of eyes had eye hypertension.

Fundus lesions were dominated by hypertensive retinopathy (41.66\%).

In addition, we observed a case of retinal detachment in a diabetic patient and a case of occlusion of the central vein of the retina.

The frequency of eye involvements decreased as the duration of dialysis increased. However, there was no correlation between cataract $(P=0.354)$, 
Table 1. Distribution of patients according to the socio-demographic features.

\begin{tabular}{ccc}
\hline Socio-demographic features & Numbers & Percentage (\%) \\
\hline Age (years) & 6 & \\
\hline 20 & 36 & 27.54 \\
$20-39$ & 74 & 56.06 \\
40 to 59 & 16 & 12.12 \\
$\geq 60$ & & \\
\hline Gender & 79 & 59.84 \\
Male & 53 & 40.16 \\
Female & & 25.76 \\
\hline Occupation & 34 & 53.78 \\
\hline Informal sector & 71 & 7.59 \\
Pupils and students & 10 & 12.87 \\
\hline Unemployed & 17 & \\
\hline
\end{tabular}

Table 2. Distribution of patients according to anterior segment involvements.

\begin{tabular}{|c|c|c|c|}
\hline Structures & $\mathrm{AS}^{*}$ involvements & Numbers & Percentage (\%) \\
\hline \multirow{5}{*}{ Cornea } & Normal & 104 & 78.78 \\
\hline & diffuse $\mathrm{SPK}^{\star *}$ & 23 & 17.42 \\
\hline & Corneal scarring & 3 & 02.27 \\
\hline & Staphylome & 1 & 0.75 \\
\hline & Ulcer & 1 & 0.75 \\
\hline \multirow[t]{3}{*}{ Anterior chamber } & Normal & 130 & 98.48 \\
\hline & Tyndall & 2 & 01.51 \\
\hline & Normal & 101 & 76.51 \\
\hline \multirow[t]{2}{*}{ Iris } & $\begin{array}{l}\text { Posterior } \\
\text { Synechiae }\end{array}$ & 3 & 02.27 \\
\hline & Rubeosis & 1 & 0.75 \\
\hline \multirow[t]{2}{*}{ Pupil } & Normal & 128 & 96.96 \\
\hline & Semi-mydriasis & 4 & 03.03 \\
\hline \multirow[t]{2}{*}{ Cristallin } & Normal & 95 & 71.96 \\
\hline & Cataract & 37 & 28.03 \\
\hline
\end{tabular}

${ }^{*} \mathrm{AS}=$ anterior segment. ${ }^{*} \mathrm{SPK}=$ Superficial Punctuated Keratitis.

conjunctival calcifications ( $\mathrm{P}=0.397)$, conjunctival hyperemia $(\mathrm{P}=0.823)$, palpebral edema $(P=0.273)$, dry eye $(P=0.303)$ and the duration of dialysis. There was no correlation between HR $(\mathrm{P}=0.187), \mathrm{DR}(\mathrm{P}=0.123)$, optic neuropathy ( $\mathrm{P}$ $=0.251)$ and duration of dialysis. 


\section{Discussion}

In our series, the most common functional signs were loss of visual acuity (37.12\%) and eye pruritus (22.72\%). This result was superior to that of Karim [4] who mentioned a loss of visual acuity (LVA) in $26.6 \%$ of cases [4]. This LVA could be explained on the one hand by refractive errors found most often in chronic hemodialyzed patients and, on the other hand, by the occurrence of certain pathologies such as cataract. For Flament [5], eye pruritus was the most dominant functional sign. It may be due to uremia [5]. He also argued that refractive errors were very common and accounted for (30\%). And these refractive errors were responsible for much of the loss of visual acuity in patients on hemodialysis [5].

The anterior segment involvements were dominated by cataract $(28.03 \%)$ (Table 2, Table 4). This result was similar to that of Ndiaye [2] who reported the presence of cataract in $26.8 \%$ of the eyes [2]. Karim [4] said the same thing with a frequency of $22 \%$. Phosphocalcic disturbances, age, duration of hemodialysis, long-term corticosteroid therapy for pre-existing nephropathy and the role of oxidative stress are discussed in the genesis of cataract [5]. In our study, we found that cataract was not age-related with a probability $(P=0.112)$. We could thus conclude that hemodialysis is a factor promoting the occurrence of cataract. However, we also found no correlation between Opacification of the lens and dialysis in this study $(\mathrm{P}=0.356)$. Iris lesions were essentially sequelae of uveitis ( 3 cases of posterior synechiae). They are described in several systemic and inflammatory renal disorders such as Behcet's disease, systemic lupus erythematosus and sarcoidosis [6]. These uveal signs could be related to undiagnosed systemic diseases. The case of rubeosis of the iris observed in neovascular glaucoma was the complication of proliferative diabetic retinopathy.

Eye hypertonia was noted in $7.96 \%$ of the eyes. This result was superior to that of Ndiaye [2] and Hachache [7] who found $2.7 \%$ and $1.23 \%$ of ocular hypertension respectively. Indeed, according to Flament [5], the increase in intra ocular pressure during dialysis is possible, and could create a picture of acute hypertonia. It can disturb the course of a hemodialysis and cause headaches and nausea. It is related to a change in the osmolar gradient between plasma on the one hand and aqueous humor and cerebrospinal fluid on the other hand following delayed elimination of urea [5]. These pressure variations can be reduced by performing more frequent, shorter-term dialysis sessions and also by the use of high-speed hemodialysis [5]. In contrast, Biard [8] pointed out the existence of marked hypotonia occurring after hemodialysis sessions. In our study, we also reported $1.84 \%$ of cases of ocular hypotonia.

In the fundus, hypertensive retinopathy was the most common (Table 3, Table 4 ). In our series, we diagnosed $41.66 \%$ of hypertensive retinopathy. Ndiaye [2] also reported a higher frequency (75.9\%). This predominance of hypertensive retinopathy in our study may be justified by the fact that hypertension is the predominant history. In addition, this high proportion could be explained by the 
Table 3. Distribution of patients according to fund us anomalies.

\begin{tabular}{cccc}
\hline Retinal field & Lesions & Numbers & Percentage (\%) \\
\hline \multirow{2}{*}{ Macula } & Dry Exsudates & 19 & 14.39 \\
& Dull Reflection & 8 & 6.06 \\
Drusens & 4 & 3.03 \\
Scars & 3 & 2.27 \\
& Epimacular membrane & 1 & 0.75 \\
Papilla & LODC & 14 & 10.6 \\
& Temporal pallor & 17 & 12.87 \\
& Edema & 9 & 6.81 \\
& Optic atrophy & 2 & 1.51 \\
& Prepapillary membrane & 1 & 075 \\
& Hypertensive retinopathy (HR) & 55 & 41.66 \\
Retinal field & Diabetic retinopathy (DR) & 8 & 6.06 \\
& Mixed retinopathy & 21 & 15.9 \\
& HIV-related retinopathy & 2 & 1.51 \\
& & &
\end{tabular}

Table 4. Distribution of patients according to the manifestations of the eye and the appendages in comparison with the duration of the dialysis.

\begin{tabular}{|c|c|c|c|c|c|c|c|c|}
\hline \multirow[b]{3}{*}{$\begin{array}{l}\text { Ophthalmologic } \\
\text { manifestations }\end{array}$} & \multicolumn{8}{|c|}{ Duration of dialysis } \\
\hline & \multicolumn{2}{|c|}{$\begin{array}{c}\text { [6 months-2 years }] \\
(n=37)\end{array}$} & \multicolumn{2}{|c|}{$\begin{array}{l}{[2 \text { years }-4 \text { years }]} \\
\quad(n=54)\end{array}$} & \multicolumn{2}{|c|}{$\begin{array}{l}\text { [4 years-6 years] } \\
\quad(\mathrm{n}=24)\end{array}$} & \multicolumn{2}{|c|}{$\begin{array}{c}\text { More than } 6 \\
\text { years }(n=17)\end{array}$} \\
\hline & Numbers & $\%$ & Effectifs & $\%$ & Effectifs & $\%$ & Effectifs & $\%$ \\
\hline Adnexias and & & & & & & & & \\
\hline Anterior Segment & 3 & 8.1 & 8 & 14.81 & 1 & 4.16 & 0 & 0 \\
\hline Palpebral edema & & & & & & & & \\
\hline $\begin{array}{l}\text { Conjunctival } \\
\text { calcifications }\end{array}$ & 1 & 2.7 & 2 & 3.7 & 2 & 8.33 & 0 & 0 \\
\hline Hyperemia & 1 & 2.7 & 6 & 11.11 & 0 & 0 & 0 & 0 \\
\hline Dry Eye & 5 & 13.51 & 9 & 16.66 & 3 & 12.5 & 3 & 17.64 \\
\hline diffuse SPK & 12 & 32.4 & 7 & 12.96 & 4 & 16.66 & 0 & 0 \\
\hline Cataract & 7 & 18.91 & 21 & 38.88 & 8 & 33.33 & 1 & 5.88 \\
\hline $\begin{array}{c}\text { Fundus } \\
\text { HR }\end{array}$ & 22 & 66.66 & 30 & 65.21 & 2 & 10.51 & 1 & 5.88 \\
\hline $\mathrm{DR}$ & 7 & 16.66 & 1 & 2.17 & 0 & 0 & 0 & 0 \\
\hline Optic neuropathy & 6 & 33.33 & 15 & 32.6 & 6 & 31.57 & 5 & 29.41 \\
\hline
\end{tabular}

fact that all patients have dialysis only twice a week, whereas the literature recommends at least three [1]. Indeed, hypertension is often controlled by dialysis which leads to a decrease in the frequency, or even a reduction in the severity of hypertensive retinopathy. In Côte d'Ivoire, and in Abidjan in particular, the in- 
adequate number of hemodialysis per week could be explained by the increase in the incidence of chronic renal failure patients, while the hemodialysis centers are inadequate without, however, omitting the precarious socio-economic situation of our patients and the lack of social security, which is a hindrance to the regularity of dialysis sessions.

Pallor of the fundus, observed in $12.87 \%$ of the eyes, was one of the most frequent manifestations in the posterior segment [5]. Ndiaye [2] noted the pallor of the fundus in $3 \%$ of the cases. Anemia was the main cause according to Flament [5]. However, this pallor tends to disappear more and more, given the antianemics frequently used in dialysis to correct anemia.

Macular lesions were dominated by macular edema (dry exudates) (14.39\%). This edema is an integral part of hypertensive and/or diabetic retinopathy. In addition, macular drusens (3.03\%) were observed. Ndiaye [2] noted $2 \%$ macular drusens. For Flament [5] and Mesaric [9], these macular drusens were more rare and without specificities. Cases of macular scars have also been noted in the literature [5].

Papillary involvements were polymorphous, represented by temporal pallor (12.87\%), large pathological optic disc cupping (10.60\%), edema (6.81\%) and optic atrophy (1.51\%). In Ndiaye's study [2], papillary involvements were dominated by edema observed in $14.8 \%$ of cases. For him, these edemas were observed most often at the onset of the disease at the time when hypertension is not controlled. This was the case in our study where these edemas corresponded to stage 3 of the Kirkendall hypertensive retinopathy.

The large pathological optic disc cupping was also observed by Ndiaye [2] who noted $5.5 \%$ of cases. These cuppings could be justified by nyctohemeral changes in blood pressure. Arterial hypotension, especially nocturnal or after the institution of hypotensive treatment, could play a significant role in the genesis of optic disc cupping [5]. Ndiaye [2] also observed $6.4 \%$ of cases of optic atrophy. This atrophy may be the consequence of numerous cases of ischemic optic neuropathy described in the patient on dialysis [5]. This ischemic optic neuropathy would be secondary to hypotension induced by dialysis, anemia and atherosclerosis [5]. For Karim [4], the ophthalmological examination performed at a distance from the optic involvement makes the etiological diagnosis of atrophy difficult. Sequelar optic atrophy may also be due to compression of the optic fibers secondary to prolonged papillary edema [5]. A too rapid decrease in blood pressure in hypertensive patients with papillary edema may be responsible for ischemic optic neuropathy [10] [11]. Other fundus involvements have been described. This is retinal detachment. This detachment is exudative during CRF [1] [5]. It is bilateral and regresses in a few days after the control of hypertension [1] [5]. In our work, we observed a case of unilateral retinal detachment in a diabetic patient. Vascular thromboses are also described in the chronic hemodialysis patient. They are attributed to arteriolar thrombosis secondary to chronic arterial hypotension and frequent atheroma [5]. In our study, we recorded a case of retinal vein occlusion of the central vein of the retina. Hachache [7] reported a 
case of venous thrombosis.

Concerning appendages, cases of ophthalmoplegia have been described in the literature [5]. Can [12], noted the disappearance of this ophthalmoplegia following dialysis and this allowed him to discuss the role of certain toxins in neuropathies of CRF. These toxins were mainly urea, creatinine, parathyroid hormone, myosinotol, transketolase and guanidine derivatives.

Most of chorioretinal and papillary changes were not a particular clinical entity and would result from hypertension, arteriosclerosis, anemia according to Flament [3].

The study could not determine a correlation between hypertensive retinopathy and duration of hemodialysis $(\mathrm{P}=0.187)$. There was no other correlation between the duration of hemodialysis and cataract $(P=0.354)$. According to the literature, there is a significant correlation between the duration of dialysis and the occurrence of eye involvements [5]. In this series, we observed a decrease in eye involvements as the duration of dialysis in years increased, contrary to Hachache's study [7].

\section{Conclusion}

Eye manifestations in chronic hemodialysis patients are variable. They are rarely mentioned in hemodialysis. They are sometimes serious, disabling and are mainly represented by hypertensive retinopathy. Hence, there is the need to perform a perfect blood pressure control in the patient on hemodialysis and to repeat fundus examination regularly. These eye manifestations found are not directly related to hemodialysis. However, a better follow-up of patients would be necessary in order to prevent them from having a double handicap and being a social burden.

\section{Institution of Origin of the Study}

Ophthalmology Department, Cocody University Hospital, Abidjan, Côte d'Ivoire.

\section{Conflicts of Interest}

The authors declare no conflicts of interest regarding the publication of this paper.

\section{References}

[1] Maurizi-Balzan, J. and Zaoui, P. (2003) Insuffisance rénale chronique, Néphrologie, Corpus médical-Faculté de médecine de Grénoble. Ellipses Ed, 253, 1-6.

[2] Sow Ndiaye, M.N., et al. (2010) Les lésions oculaires chez le patient mélanoderme atteint d'insuffisance rénale chronique. Mali Medical, 25, 14-20.

[3] Bourquia, A., et al. (1992) Les manifestations ophtalmologiques chez les hémodialysés chroniques. Annales de Médecine Interne, 143, 18-21.

[4] Karim, I., et al. (2016) Les manifestations ophtalmologiques chez les hémodialysés chroniques. Consulté le 17 octobre 2016 à $18 \mathrm{~h}$.

[5] Flament, J. and Storck, D. (1997) Eil et pathologie générale. Rapport SFO, Masson, 
Paris, 494-517.

[6] Regenbogen, L., Coscas, G. and Debbasch, S. (1995) Eil et rein. Encycl. Med. Chir. (Paris, France), Ophtalmologie, 21-453-A-25, 9.

[7] Hachache, T., et al. (1996) Manifestations Ophtalmologiques du dialysé. Etude rétrospectives sur 81 patients. Néphrologie, 17, 117-121.

[8] Biard, L., et al. (1977) Ophthalmologic Aspects of Chronic Hemodialysis. Annales de Médecine Interne, 128, 537-539.

[9] Mesaric, B. (1974) Examen systématique des modifications pathologiques des yeux des malades souffrant d'insuffisance rénale chronique. Archives of Ophthalmology, 12, 907-916.

[10] Korzets, A., Marashek, I., Schwartz, A., Rosenblatt, I. and Herman, M. (2004) Ischemic Optic Neuropathy in Dialyzed Patients: A Previously Unrecognized Manifestation of Calcific Uremic Arteriolopathy. American Journal of Kidney Diseases, 44, 93-97. https://doi.org/10.1053/j.ajkd.2004.08.035

[11] Kishi, I., Tso, M. and Hayreh, S. (1985) Fundus Lesions in Malignant Hypertension II A Pathological Study of Experimental Hypertensive Optic Neuropathy. Archives of Ophthalmology, 103, 1198-1206.

https://doi.org/10.1001/archopht.1985.01050080110030

[12] Can, U., Aydin, P. and Kansu, T. (1994) Bilateral External Ophthalmoplegia in Uremia. Nephron, 68, 391. https://doi.org/10.1159/000188410 